\title{
A Dual-Model of Posttraumatic Stress and Posttraumatic Growth in a Community Sample of Female Conflict-Related Sexual Violence Survivors from Bosnia \& Herzegovina
}

Kimberley Anderson ( $\nabla$ kanderson880@gmail.com )

Reinier van Arkel https://orcid.org/0000-0002-2500-3078

Ivan Komproe

HealthNet TPO

Amra Delić

Universitat Greifswald

Esmina Avdibegović

Univerziteta u Tuzli Medicinski Fakultet

Elisa van Ee

Reinier van Arkel

Heide Glaesmer

Universitatsklinikum Leipzig

Research article

Keywords: sexual violence, Bosnia \& Herzegovina, posttraumatic growth, PTGI, coping

Posted Date: August 7th, 2019

DOI: https://doi.org/10.21203/rs.2.12466/v1

License: (c) (i) This work is licensed under a Creative Commons Attribution 4.0 International License.

Read Full License

Version of Record: A version of this preprint was published on September 1st, 2020. See the published version at https://doi.org/10.7590/266644720X15989693725702. 


\section{Abstract}

Background: Posttraumatic stress disorder (PTSD) and posttraumatic growth (PTG) are increasingly acknowledged as psychological outcomes that can co-occur in the aftermath of a traumatic event. Less clear however, is how these outcomes interact - particularly for female survivors of conflict-related sexual violence (CRSV) - and to what extent intermediary factors such as coping play a role in this relationship. Methods: In a sample of 192 survivors of the 1990s conflict in Bosnia \& Herzegovina; of whom 104 experienced CRSV, and 88 who did not, a structural equation model was tested using LISREL 8.8 that included CRSV as a traumatic event, 'positive reinterpretation' (as a strategy of approach coping) and 'behavioural disengagement' (as a strategy of avoidance coping), and PTSD and PTG as psychosocial outcomes. It was hypothesised that there would be differences in the mechanisms by which PTG and PTSD interact in the two subgroups, given the differences in the nature of the trauma they experienced. Results: Through multiple indirect relationships, results showed that CRSV survivors respond to their trauma with both PTSD and PTG, substantiating a dual PTSD-PTG mechanism, as opposed to a single spectrum with these outcomes at the poles. With regard to coping strategies, positive reinterpretation predicted greater PTG, and behavioural disengagement predicted greater PTSD. In the sample of nonsexual violence survivors, positive reinterpretation also remained a significant predictor of PTG. Conclusions: Findings suggest that positive reinterpretation as a coping strategy appears to be a stable characteristic that independently predicts PTG, irrespective of trauma type. Mental health care professionals should take into account this specific mechanism when addressing the needs of CRSV survivors, but also war survivors more generally. Reframing traumatic events and post-trauma sequalae during treatment could lead to greater PTG and enhance recovery.

\section{Background}

The development of posttraumatic growth (PTG) in the aftermath of a traumatic event is a salutary association, and is something that is increasingly investigated across mental health literature (e.g. Mittelmark \& Bauer, 2017). Debate still remains however, as to how this is association is impacted by other factors and how it differs across different types of events (Ulloa, Guzman, Salazar, \& Cala, 2016). Posttraumatic growth is understood as a "significant beneficial change in cognitive and emotional life that goes beyond previous levels of adaptation or psychological functioning, and is a way of living optimally in the wake of trauma" (Tedeschi, Park, \& Calhoun, 1998, pg. 1). Some suggest that PTG can be viewed as a defence against the development of pathology in the wake of a traumatic event (Dekel, EinDor, \& Solomon, 2012), but it is likely to be more complex. There is moderate support for a curvilinear relationship between posttraumatic stress disorder (PTSD) symptomatology and PTG, whereby fewer PTSD symptoms may not be enough stimulation for a person to experience PTG, and a greater number of symptoms may result in additional mental health consequences that prevent the opportunity for PTG (Kleim \& Ehlers, 2009; Solomon \& Dekel, 2007). Other evidence suggests that adjustment to trauma is a process influenced by factors that pre-date the trauma (e.g. socioeconomic status, family stability, a history of trauma) or psychosocial factors (e.g. personality, coping strategies, social support), as well as 
event characteristics (e.g. type, intensity, duration of exposure or perceived threat) (Lawrence \& Fauerbach, 2003).

Taking the type of event as an important factor in the possible development of psychological sequalae following trauma, differences begin to emerge. Events experienced by groups of people (e.g. natural disasters) tend to result in a strengthened common identity, manifestations of solidarity and strengthened self-esteem (Garcia \& Rimé, 2019). Events experienced personally by an individual, such as that of interpersonal violence of a sexual nature, can trigger a more complex reaction, including high rates of depression, anxiety and PTSD (Verelst, De Schryver, Broekaert, \& Derluyn, 2014). In some contexts, additional factors can contribute to subsequent outcomes. For example, how controllable the event was to the victim; whether they attribute the occurrence of the event to a personal characteristic or whether it was under the control of another person or entity. Moreover, if a survivor of sexual violence negatively appraises their emotions and symptoms, or indeed if they perceive negative responses from others, there is a greater risk of developing PTSD (Chivers-Wilson, 2006). This often stems from the shame and stigma that is associated with this type of violence, particularly in conflict settings (Mukwege \& Nangini, 2009), that may be perceived differently to other non-interpersonal, war-related trauma, such as the death of a loved one. Findings from Verelst, De Schryver, De Haene, Broekaert, \& Derluyn (2014) among adolescent girls in the Democratic Republic of the Congo showed that stigmatisation related to sexual violence has a greater mediating impact on mental health outcomes, than of the act itself.

With regard to psychosocial factors, it is understood that coping is the process by which people manage their stress following a traumatic event; either by doing something to alter the source of the stress, or by managing the emotional reactions associated with it (Carver, Scheier, \& Weintraub, 1989). Several scholars (Brooks, Graham-Kevan, Robinson, \& Lowe, 2018; Elderton, Berry, \& Chan, 2017; Ullman, 2014) have found approach coping styles (where a person seeks to resolve the stressor) to be positively correlated with PTG in people with experiences of interpersonal violence; with the inverse (actively avoiding the stressor) negatively associated with PTG. Furthermore, Cole (2008) found that male and female survivors of sexual violence who disclosed their assault (as form of approach coping) were more likely to experience PTG. This is a particularly important aspect of recovery for survivors, given that withdrawal from social networks often takes places in the aftermath of interpersonal trauma of a sexual nature (Kılıç, Magruder, \& Koryürek, 2016). In other research however, positive relationships between avoidance strategies and psychological outcomes have been identified. Verelest and colleagues (2014) found that while certain symptoms may stem from direct emotional and psychophysiological responses to reliving traumatic sexual events, symptoms of avoidance may constitute a marker of a stigmatized social position within the individual's family and community. Another explanation for this, as posited by Littleton (2003), is that the use of avoidance strategies among women may be more commonly associated with greater distress in the aftermath of sexual violence, because the tendency to suppress thoughts about the stressor or denying that it exists, may paradoxically lead to over-attention to the event. This may initially serve as a protective mechanism to mitigate emotional distress following trauma (London, Mercer, \& Lilly, 2017). However, among other populations, research suggests that avoidance 
coping strategies can lead to more positive adaptations in the short term, but have no, or even negative, effects in the long term (van Elderen, Maes, Madalinska, \& Komproe, 1996).

In a previous study based on the dataset presented in this article (Anderson et al., 2019) findings from women in Bosnia \& Herzegovina who experienced CRSV during the war from 1992-1995, showed that higher levels of positive reinterpretation (as a form of approach coping; i.e. seeing a situation in a favourable light) and lower levels of behavioural disengagement (as a form of avoidance coping; i.e. withdrawing effort from achieving the goal with which the stressor interferes) were associated with a greater degree of PTG. These domains of coping likely represent mediators of pathogenic and salutary outcomes: positive reinterpretation as a buffer against and behavioural disengagement as a risk factor for, lower measured PTG. Regression analyses indicated that severity of posttraumatic symptomatology was not significantly associated with PTG, which may be attributable to the fact that PTSD was identified in more than $90 \%$ of the sample.

Nonetheless, such findings can only tell us so much. We know that coping provides a person with the emotional and behavioural tools to appraise and assess a situation for threat, which can be a protective factor in times of distress and buffer against psychological suffering. However, whether this occurs directly (where an increase in coping skills will result in an increase in PTG irrespective of the existing level of PTSD) or indirectly (protecting persons from the potentially pathogenic influence of stressful events) remains unclear. Prior analyses have potentially been too simplistic. This occurs particularly as a result of the difficulty in obtaining retrospective data in certain populations and a reliance on crosssectional studies, and therefore an inability to make causal inferences (Cole \& Lynn, 2010). Given the evidence, the most likely interaction is that events themselves do not result directly in PTG (Brooks et al., 2018), but individuals will respond to stress with a mixture of resilience-promoting resources and vulnerability to mental illness (Kuwert et al., 2014; Shakespeare-Finch \& Lurie-Beck, 2014)-a dual mechanism-rather than PTG falling on the 'adaptive' end of a single spectrum of post-trauma adjustment (Tedeschi \& Calhoun,1996). This results in multiple indirect relationships between trauma, PTG and PTSD that may be impacted by psychosocial factors such as coping. The purpose of this paper is to delve deeper into the possibility of a dual mechanism by which PTG and PTSD interact in the aftermath of trauma, and to explore the extent to which they are impacted by certain coping strategies.

On the basis of the literature outlined above (Brooks et al., 2018; Elderton et al., 2017; Kuwert et al., 2014), and the findings of our previous study (Anderson et al., 2019) a model of PTG was defined. The core assumption is that the relationship between CRSV and PTG is mediated by psychosocial factors such as coping. Multiple indirect relationships are suggested, that specify strategies of coping that buffer against PTSD and promote PTG, and contribute to explaining this dual mechanism. These assumptions are tested using a structural equation modelling approach within a sample of CRSV survivors from Bosnia \& Herzegovina, and compared to a group of war survivors who did not experience CRSV. We have three main hypotheses: 1) that PTG and PTSD will both be possible psychosocial outcomes among this waraffected population; 2) that the explanatory mechanisms for PTG among CRSV survivors will be different from participants who did not experience CRSV, and 3) that higher measured PTG among CRSV survivors 
will be associated with greater positive reinterpretation as an approach coping strategy, and lower behavioural disengagement as an avoidance coping strategy. A more detailed understanding of these mechanisms - the interrelationships and the differences between those who experienced CRSV and those who did not-will shed light onto the dual PTSD-PTG mechanism and might have important implications for how to support survivors of CRSV towards PTG and recovery.

\section{Methodology}

\section{Design and setting}

The data presented here are part of a cross-sectional study on the quality of life and long-term psychological consequences among women with experience of CRSV during the conflict in Bosnia \& Herzegovina. During this conflict, women are believed to have been subject to CRSV by civilians; locallystationed and foreign military forces (Benard, 1994; Delić, Kuwert, \& Glaesmer, 2017; Salzman, 1998; Skjelsbæk, 2006) and even peacekeepers (Jennings \& Nikolić-Ristanović, 2009). We refer to the United Nations definition of CRSV, as "rape, sexual slavery, forced prostitution, forced pregnancy, forced abortion, enforced sterilization, forced marriage, and any other form of sexual violence of comparable gravity perpetrated against women, men, girls or boys that is directly or indirectly linked to a conflict" (United Nations, 2017, pg. 3). Data used in this study were collected by the research team from December 2012 to December 2014, 20 years after the start of the war. Results elsewhere have shown that more than half of female sexual violence survivors still suffered from PTSD more than two decades after the start of the war (Medica Zenica \& medica mondiale, 2014). Ethical approval was given by the Human Research Ethics Board of the Medical Faculty of the University of Tuzla, Bosnia and Herzegovina.

\section{Participants and procedures}

Female survivors of CRSV in this study were recruited by author AD, with the assistance of the Bosnian non-governmental, non-profit 'Association for Women Victims of War', who campaign for the rights of women and girls who experienced sexual violence during the conflict, and possess a database of more than 700 CRSV survivors (CRSVs). Participants were eligible for inclusion in this study if they had been residents of Bosnia \& Herzegovina during and after war and were between 30-65 years old at the time of study. On the basis of a study screening measure of cognitive functioning (Mini Mental Status Examination, MMSE; Folstein, Folstein, \& McHugh, 1975) women were excluded with scores $₫ 23$ (out of a possible score of 30 , with 24 indicating normal cognition)or those with a psychiatric history prior to the war. Participants for the CRSVs group were eligible if they had experienced sexual violence during the years 1992-1995, and had disclosed this to the association. A control group of women who did not experience sexual violence during the war (non-CRSVs), but met other study criteria, was selected from the general population using a method of snowball sampling.

A multistage sampling method was employed to reach the civilian population who experienced sexual violence during the war. Seven localities across Bosnia and Herzegovina were identified as having the 
greatest density of registered CRSVs, and using the list of registered female members of the association, the President telephoned survivors from selected localities to provide them with information about the research project and to invite them to voluntarily participate in the study. For those who consented, the initial interview was then conducted in person by $A D$ in two or more sessions, with breaks upon request. Psychiatric history was discussed with participants and corroborated by medical notes if these were available. Given the sensitive nature of the research, referral information for psychological counselling and support was provided.

Interviews were carried out with a total of 110 CRSVs; of which three later withdrew their consent, two were excluded due to MMSE $\mathbb{2} 23$, and one participant was excluded due to missing data. A contact person from the local NGOs, mental health facilities or psychiatric clinics that provided space for interviews for CRSVs was asked to recommend other women who may be willing to participate. Those who were interviewed were asked to identify other potential participants, who were then contacted and followed-up. This gave a total sample of $n=192$ for analysis, see table 1 for details.

$<$ Insert table 1 about here >

\section{Measures}

\section{Socio-demographic questionnaire: A self-developed questionnaire was developed by author $A D$ to gather sociodemographic data (including ethnic affiliation, age, marital status, education, employment status, data on the context of CRSV, and any involvement in psychosocial support programmes).}

Harvard Trauma Questionnaire (HTQ; Mollica, Caspi-Yavin, Bollini, \& Truong, 1992): a version for Bosnia and Herzegovina (Allden et al., 1998) was used to explore experiences of traumatic events and assess the presence of PTSD symptomatology. Only the first and fourth parts were used in this study. The first part is a list of possible traumatic events that civilians could potentially have been exposed to during the war, for which there is a yes/no response format. Events include material deprivation, conditions relating to war, bodily injury, forced confinement and coercion, being forced to harm others, disappearance, death or injury to loved ones, and witnessing violence to others. The fourth part contains 40 statements about possible psychosocial difficulties caused by trauma. The first 16 statements are derived from DSM-IV criteria for PTSD and inquire about the symptoms of the PTSD domains: re-experiencing the traumatic event, avoidance, and hyperarousal. The scale for each response in these sections are rated from 1 "not at all" to 4 "very strongly", whereby a mean item score of 2.5 or above is considered an indicator for 
symptoms of PTSD. Symptoms are grouped into three phenomena: re-experiencing traumatic experiences, avoiding and numbing, and psychological arousal, of which there are 4, 7 and 5 items respectively. This measure has been used reliably in a study of Bosnian women affected by war (Klaric et al., 2008) with reportedly high internal consistency for traumatic symptoms (Cronbach's $a=0.95$ ). In this study, the HTQ demonstrated very high reliability and internal consistency with Cronbach's $a=0.96$ for the PTSD symptom scale.

Coping Orientations to Problems Experienced Scale (COPE; The Bosnian version used in this study is an adaption of the validated Croatian COPE scale, Hudek-Knežević, Kardum, \& Vukmirović, 1999): is a 71item scale to assess how people respond when they are confronted with difficult or stressful situations, whereby respondents rate each statement on a scale from 0 "never" to 4 "I always do this". It produces 15 subscales that mirror the original COPE-60 (Carver et al., 1989), which include problem-focused, emotionfocused and disengagement dimensions, and reflect the activities from a particular coping domain. Subscales are calculated using the mean score of items. Based on results from prior research (Anderson et al., 2019) two subscales were used in this study: 'positive reinterpretation' is comprised of 4 items (e.g. "I try to make it seem more positive"), and behavioural disengagement is comprised of 5 (e.g." I admit to myself I can't deal with and quit trying"). In the validated Croatian version, 'substance use' referred exclusively to alcohol, in the Bosnian translation, this referred only to the use of sedatives. This scale has been used successfully in existing research (see Antičević, Kardum, \& Britvić, 2011, for results on the impact of traumatic experiences on Croatian war verterans). In this study, positive reinterpretationreframing negative experiences-had an alpha of.57 and behavioural disengagement-withdrawing effort from addressing the source of stress $-a .72$.

Posttraumatic Growth Inventory (PTGl; Tedeschi \& Calhoun, 1996): The PTGI is a 21-item self-report scale for assessing psychological growth following a traumatic event, in this case framed in the context of participants' experiences of CRSV. The PTGI includes five subscales: new possibilities (e.g., "I established a new path for my life"), relating to others (e.g., "I feel a sense of closeness with others"), personal strength (e.g., "knowing I can handle difficulties"), spiritual change (e.g., "I have a stronger religious faith"), and appreciation for life ("I appreciate each day"). Total scores on the PTGI range from 1 to 126 , with higher scores reflecting greater perceived growth, and items uses a response format that ranges from 1 ("I did not experience this change as a result of my crisis") to 6 ("I experienced this change to a very great degree as a result of my crisis"). The PTGI has been successfully implemented in a study of Israeli war veterans (Dekel et al., 2012), who report high reliability for total scores (Cronbach's $a=0.94$ ). In the present study, Cronbach's $a$ for the PTGI total score was 0.96 and ranged from 0.66 to 0.90 for subscale scores.

\section{Data analyses}

The samples of CRSVs and non-CRSVs, were first tested on differences in sociodemographic characteristics using t-tests and chi-square tests. T-tests were also used to compare means of study 
outcome variables.

We then defined a conceptual model and assessed the extent to which it fits the data within the total sample, and separately for the groups CRSVs and non-CRSVs. The hypothesised model was evaluated with structural equation modelling using LISREL 8.8 (Jöreskog \& Sörbom, 2006). Five goodness-of-fit measures used in this study were: 1$)$ chi-square $\left(\chi^{2}\right)$ as a measure of the discrepancy between variancecovariance matrices of the variables used in the model; and the (constructed) variance-covariance matrix derived from the specified relationships in the model. A non-significant $\chi^{2}$ refers to the resemblance between the specified relationships in the hypothesised model and interpretations of the variances-covariances in the data matrix (i.e. validity of the structural equation model (SEM) explaining the (co)variances of the data matrix); 2) the root-mean-square error of approximation (RMSEA) which refers to the difference between the data variance-covariance matrix and the model-based matrix fit to the data, per degree of freedom. This estimate should be less than.05 to indicate close fit. Confidence intervals (90\%) of RMSEA are provided; 3 ) comparative fit index (CFI) which assumes that all latent variables are uncorrelated and compares the sample covariance matrix with this null model. Values for this statistic range between 0.0 and 1.0 with values closer to 1.0 indicating good fit; 4) standardized root mean square residual (SRMR) which assess the difference between the residuals of the sample covariance matrix and the hypothesised covariance model. Values for the SRMR range from zero to 1.0 with well-fitting models obtaining values less than.05; and 5) non-normed fit index (NNFI), which assesses the model by comparing the $\chi^{2}$ value of the model to the $\chi^{2}$ of the null model. Values for this statistic range between 0 and 1 with values greater than 0.90 indicating a good fit.

Statistical modelling was done by inclusion and exclusion of relationships between variables, that, underpinned by theory and supported by modification indices provided by the LISREL software, gave alternative models. These alternative models are evaluated by means of the five goodness-of-fit measures. Only standardized estimated paths with $t$ values $>1.98$, thus only paths with a significance of $p<.05$, are included in the modelling process. Relative effect sizes are defined using standardised path coefficients, as seen in figures 2-4. The 'most likely best-fitting' (MLBF) model and its specified relationships obtained from the CRSVs group was then tested on the non-CRSVs group. This type of statistical modelling has been used successfully elsewhere in mental health research to predict healthcare consumption (Kamperman, Komproe, \& de Jong, 2007), community social capital (Wind \& Komproe, 2012), and postpartum posttraumatic stress (van Son, Verkerk, van der Hart, Komproe, \& Pop, 2005).

Lastly, post hoc multi-group analyses were conducted to determine whether the model performed differently as a function of subgroup, by estimating the model freely for CRSVs and non-CRSVs. This unconstrained model was then compared to models in which the parameters were constrained to be equal across groups. In doing so, it is possible to test specific hypotheses about group differences by constraining individual parameters and then comparing model fit (Bosmans et al., 2015; Jordans, Komproe, Tol, \& De Jong, 2009; Kamperman et al., 2007). 
On the basis of earlier analyses and existing literature on the subject, the hypothesised model specified five pathways between experiencing CRSV; positive reinterpretation and behavioural disengagement as strategies of coping; and PTSD severity and PTG as psychosocial outcomes. At the core of the hypothesised model, several indirect relationships were specified between the experience of sexual violence and PTG: on one hand 1) experiencing CRSV can lead to higher PTSD scores which may result in lower measured PTG; 2) CRSV can lead to the use of behavioural disengagement (as an avoidance coping strategy), which could lead to lower measured PTG; and 3) this second pathway could be further mediated by PTSD. On the other hand, 4) the experience of CRSV could lead to positive reinterpretation of the event (as an approach coping strategy) which could result in higher measured PTG; and 5) this relationship could be further mediated by behavioural disengagement and has a negative impact on PTG. Given the difference in trauma types between the subsamples and the mechanisms by which coping influences psychosocial outcomes, the final model for the non-sexual violence survivors is expected to fit differently. The hypothesised model is presented in figure 1.

\section{$<$ Insert figure 1 about here >}

\section{Results}

The total study sample comprised 192 female participants ( $n=104$ CRSVs and $n=88$ non-CRSVs). The largest proportion of women in both groups were of Bosniak ethnicity, but survivors of sexual violence were significantly older than non-CRSVs. Fewer CRSVs were married, educated above primary school level or currently employed. Regarding the circumstances of sexual violence, $45.2 \%(n=47)$ of women indicated that they were raped three or more times during the conflict, with almost a third $(29.8 \%, n=30)$ having been raped by three or more perpetrators. The majority of women $(76 \%, n=79)$ did not know their perpetrators. Women were on average 29.6 (SD 8.9) years old (range 12-48) when their first experience of sexual violence took place. Fourteen women (13.5\%) indicated that they became pregnant as a result of being raped, of whom $10(9.6 \%)$ had this pregnancy terminated. Scores on study variables fell in the expected directions: survivors of CRSV were higher in terms of PTSD severity (current PTSD symptomatology above a threshold of $>2.5$ was detected in $92.3 \%(n=96)$ of CRSVs, and in $27.3 \%$ ( $n=$ 24) of non-CRSVs), traumatic load and behavioural disengagement; and lower on PTG and positive reinterpretation (table 1).

$<$ Insert table 1 about here >

\section{The hypothesised model}

Structural equation modelling was performed on data from 185 participants, 7 cases of non-CRSVs were removed from the analysis because of multiple missing values. The correlations between the variables specified in the hypothetical model are given in Table 2. 
The hypothesised model showed no acceptable fit with the variance-covariance matrix of the data for the total sample $\left(\mathrm{X}^{2}(2)=8.54, \mathrm{CFI}=.97, \mathrm{RMSEA}=.13, \mathrm{SRMR}=.034, \mathrm{NNFI}=.86, p<0.5\right)$. In this model, seven pathways were significant. As expected, the experience of sexual violence was significantly related to both types of coping strategies (positive reinterpretation and behavioural disengagement in positive and negative directions, respectively). Positive reinterpretation was associated with higher measured PTG, and behavioural disengagement was associated with lower measured PTG, as well as greater PTSD symptom severity. The path from PTSD to PTG produced a non-significant effect $(p>0.05)$. See figure 2.

\section{$<$ Insert figure 2 about here >}

With a theoretical underpinning and guided by modification indices provided by LISREL, the model was optimised by removing the pathway between PTSD and PTG. Remaining pathways continued to be statistically significant, but overall the model still showed no acceptable fit with the data $\left(\chi^{2}(3)=10.09\right.$, $\mathrm{CFI}=.97$, RMSEA $=.052$, SRMR $=.035, \mathrm{NNFI}=.90 p=<.05)$. The optimised model (MLBF) is shown in Figure $2 b$. Based on the rationale that the experience of CRSV generates different distress-growth mechanisms, the hypothesised model was proceeded to be tested in each individual subgroup.

$<$ Insert figure $2 b$ about here >

Adequateness of the model in the CRSVs sample

The hypothesised model showed an acceptable fit with the CRSVs data $\left(\chi^{2}(1)=1.29, \mathrm{CFI}=.99, \mathrm{RMSEA}=\right.$ $0.11, \mathrm{SRMR}=.036, \mathrm{NNFI}=.93 p=>.05)$. The relationship between coping strategies positive reinterpretation and behavioural disengagement was non-significant, though positive reinterpretation was still directly related to PTG. In addition, the negative relationship between behavioural disengagement and PTG remained significant, as well as when mediated by PTSD severity. See figure 3.

\section{<Insert Figure 3 about here>}

\section{Adequateness of the model in the non-CRSVs sample}

The hypothesised model also fit the non-CRSV data, although it was a less close fit between the data variance-covariance matrix and the model-based matrix to the data, $\chi^{2}(1)=1.30, \mathrm{CFI}=.98, \mathrm{RMSEA}=$ $0.061, \mathrm{SRMR}=.043, \mathrm{NNFI}=.91, p=>0.05)$. In this sample, PTG was still directly impacted by positive reinterpretation, but all other associations were spurious. See figure 4.

<Insert figure 4 about here>

Post hoc multi-group analyses 
Finally, we used SEM to test the presented model found in the total sample on its adequacy for both sub samples, by using a multi-group analysis. The $\chi^{2}$ for the total model with two subgroups was 8.41 (7), $\mathrm{NNFI}=0.94, p=0.30$. The $\chi^{2}$ for the earlier found model (see above) tested in the CRSV group data was 3.10 (36.87\% of total); the $\chi^{2}$ for the earlier found model (see above) tested in the non-CRSV group data was $5.31(63.13 \%)$. None of the unspecified relationships between the four variables had modification indices above 3 , thus contributing significantly to the tested model in both subsamples.

\section{Discussion}

The aim of this study was to examine the role of positive reinterpretation and behavioural disengagement as strategies of coping in understanding PTSD and PTG as psychosocial outcomes following CRSV. These variables have been documented as playing important roles in the aftermath of trauma in existing literature and earlier findings, but this is the first study to explore the interrelationships between them. Participants were part of a community-based sample from Bosnia \& Herzegovina that included both CRSV survivors and war survivors who did not experience sexual violence during the 1990 s conflict. The possibility of PTSD and PTG being separate outcomes-as opposed to opposite ends of a single spectrum-was explored, which would substantiate a dual mechanism of distress and growth. In order to investigate this mechanism in a cross-sectional dataset, SEM was used to test relationships between variables. Since we hypothesised a difference between the two subsamples (based on whether they did or did not experience CRSV), to ensure the validity of the model it was tested first overall, and then, removing the exposure variable of CRSV, we tested the model's adequacy for both subgroups. This difference was specified based on literature that distinguishes between outcomes for war-related trauma and CRSV; the difference being that uncontrollable, interpersonal events such as CRSV have the potential to challenge personal resources and characteristics (Chivers-Wilson, 2006), and come with connotations of shame (Mukwege \& Nangini, 2009) and stigma (Verelst et al., 2014), and may therefore impact the development of PTG.

Our findings offer support for our first hypothesis, that PTSD and PTG are both possible co-occurring psychosocial outcomes, substantiating the presence of a dual PTSD-PTG mechanism. Thus, it is possible for women to respond to war-related traumatic events with both distress and growth, corresponding to existing research (Kuwert et al., 2014; Shakespeare-Finch \& Lurie-Beck, 2014; Tedeschi \& Calhoun, 1996). In our model for the total sample a lower PTSD symptom severity did not predict greater PTG. By way of multiple indirect relationships, participants were more likely to experience PTG if they were able to employ a personal resource enabling them to positively reinterpret the event and subsequent psychological sequalae, by reframing the impact of their experiences.

With regards to our second and third hypotheses, our results confirmed a difference in the explanatory mechanisms when the model was tested in each subsample. The difference being that positive reinterpretation significantly predicted PTG in the subsample of CRSVs, as well as in the non-CRSV group. But an additional relationship was found between higher behavioural disengagement and greater PTSD, which reduced the amount of PTG overall, for CRSVs. Thus, this type of avoidance coping after 
experiencing sexual trauma is likely a risk factor for lower measured PTG, which supports existing findings in similar vulnerable groups (Brooks et al., 2018). Additionally, in this subsample of CRSVs, a positive relationship between PTSD and PTG was detected, which supports earlier findings from London et al. (2017), who suggest that maladaptive personal resources (such as avoidant coping that is a risk factor for psychopathology including PTSD) may influence the development of PTG. This finding may reflect the extent to which women report higher levels of PTG to offset their emotional distress (Maercker \& Zoellner, 2004), on the premise that PTG can have a constructive side, as well as an illusory side; certain aspects of self-deception or denial that positively distort beliefs, still allow for PTG to prosper. For women who survived the war but did not experience CRSV no other relationships remained significant.

The findings of this study have important implications for supporting survivors of CRSV towards recovery, particularly given that sexual trauma continues to have far-reaching and long-lasting consequences that still often go unresolved (Kuwert et al., 2010; Medica Zenica \& medica mondiale, 2014). Trauma-focused psychotherapeutic techniques that are provided to individuals experiencing PTSD (NICE, 2018) have cognitive elements that allow a person to process traumatic experiences, by altering the relationship between the original emotional response and current distress. In principle, such techniques guide individual behaviour toward a more adaptive response to trauma. A stronger salutary component, and further harnessing strategies that permit these altered relationships-such as reframing the psychological sequalae following sexual trauma-could be highly beneficial to survivors. By considering the stability of this dimension of coping as personal resource, strengthening its capacity through psychoeducation, guidance or coaching nourishes the opportunity to promote PTG. Equally, a reduction in avoidance coping strategies has been shown to enhance PTG following different types of trauma (Brooks et al., 2018), which may prevent maladaptive strategies prolonging distress long-term (Zoellner \& Maercker, 2006).

However, given the result that positive reinterpretation was a predictor of PTG across both subsamples of this study, it appears to be a key protective factor in the aftermath of trauma; acting as a buffer against lower measured PTG for war-affected persons more generally. This highlights its importance as a personal resource following different types of trauma, and could mean that this 'reframing' mechanism is a characteristic that acts as a buffer against the negative consequences of war-related trauma.

Yet, cultural and societal factors influence how trauma is managed and processed in post-conflict settings, and could explain the differences between trauma types in terms of their relationship to PTG (Kılıç et al., 2016). This is particularly given that stigmatisation towards CRSVs in some places is known to still play an important mediating role in mental health outcomes, and often has a greater impact than the act itself (Verelst et al., 2014). When discussing with survivors their experiences of CRSV, whether in treatment or research, it is important to address the needs of CRSV survivors, as perceived by themselves, as this remains key in their recovery trajectory given the specific way in which these women have experienced violence or loss, and the impact of living through war.

\section{Limitations}

Page 12/23 
Despite the strength of these findings, this study is not without limitations. Primarily, there are some methodological concerns regarding the type of measures, as well as the sampling techniques used in this study that should be considered when interpreting the findings. First, the measures implemented to acquire information on PTSD, PTG and coping were self-report questionnaires, and are therefore interpreted as subjective indicators and not objective measurements. Underreporting or misinterpretation of events or symptomatology may occur within such measures. This is particularly the case for PTSD, for which we used a screener of symptoms, but requires a subsequent clinical interview for a confirmation of diagnosis. Moreover, the low internal consistency of the COPE subscales may reflect possible discrepancies in the translation/adaption or interpretation of the scale; or a lack of rigorous cross-cultural validity of the different defined coping domains. For instance, the specific activities clustered as a subscale in the original instrument might not be contextually valid among this specific population of Bosnian women. That is to say, the coping strategies of one individual is by no means a guarantee that these are beneficial to another. Thus, we consider scores on the COPE subscales as indicators of application: a low score reflects little use of the specific collection of coping strategies, and a high score refers to a greater use of the specific coping strategies.

With regards to our sampling technique, limitations include a possible selection bias and not age matched participants. Equally, due to the small sample size, demographic associations were not corrected for in the SEM analyses and the power of the model is insufficient, which could have led to unstable goodness-of-fit estimates of the PTSD-PTG mechanism. However, we believe that this type of sampling in a post-war context such as that of Bosnia \& Herzegovina-where stigma is still ever-present; where the effects of war are still daily realties for many people; where research in general is not part of the mainstream agenda (let alone that which considers women survivors of sexual violence); and where there is no information to access the entire population of survivors of sexual violence-was currently our best option. Hopefully, the more that sexual violence is discussed in mainstream society, and the more people feel comfortable to share their experiences, the greater options we will have to implement more sophisticated sampling techniques.

We must also refer to our study design when reporting our limitations, with regard to how our results should be interpreted. Despite our efforts to frame the study in relation to CRSV, a cross-sectional design in this context is not able to discount traumatic experiences that have taken place since the conflict and the impact these may have on the development of PTG or PTSD. In addition, the development of PTG requires a period of time, and thus, a cross-sectional study cannot rigorously demonstrate the dynamic process by which it is developed. Although the temporality of personal resources such as coping suggest a certain stability, we cannot know whether the development of PTG or PTSD would have changed over time. A longitudinal design can ultimately add weight to these findings and examine the dynamic development of relationships between coping and PTG in women who have experienced sexual violence in conflict. With these in mind, the results nonetheless correspond to existing literature, and begin to further explain some of the discrepancies in the understanding on PTG. 


\section{Conclusions And Implications}

This study has shown that PTG among sexual violence survivors of Bosnia \& Herzegovina's war during the 1990s is possible, particularly when utilising personal coping resources to process the psychological sequalae. PTG in this study was not affected by severity of PTSD, which adds weight to the notion of a dual distress-growth mechanism. This is in line with Tedeschi \& Calhoun (2004), who state that "PTG and distress are essentially separate dimensions, and growth experiences do not put an end to distress in trauma survivors" (pg. 13). As such, an indirect association is identified that links high levels of disengagement to an increase in distress, which becomes a risk factor for lower measured PTG. Positive reinterpretation of events appears to be an important characteristic that independently predicts PTG across both sexual violence survivors and non-sexual violence war survivors. Harnessing this process during treatment could support the effectiveness of current interventions, and promote recovery by specifically targeting the consequences of pathogenic and salutogenic outcomes following sexual trauma.

\section{Declarations}

\section{Ethics approval and consent to participate}

The study was approved by the Human Research Ethics Board of the Medical Faculty of the University of Tuzla, Bosnia \& Herzegovina. All members of the research team underwent training in ethical research practices before carrying out the study. Study participants gave written consent to participate.

\section{Consent for publication}

Study participants gave written consent to publication of results.

\section{Availability of data and materials}

The datasets used and/or analysed during the current study are available from the corresponding author on reasonable request.

\section{Competing Interests}

The authors of this study declare no competing interests.

\section{Funding}

KA received funding for this manuscript from the European Union's Horizon 2020 research and innovation programme: Children Born of War (CHIBOW) under the Marie Skłodowska-Curie grant agreement No. 642571 , as part of her doctoral project. 
$A D$ conceptualised and designed the study and collected the data. EA oversaw data collection and contributed to the manuscript. KA entered and analysed the data and wrote the manuscript. IK oversaw data analysis and drafting the manuscript. EvE and HG contributed to drafting the manuscript. All authors read and approved the final copy of the manuscript.

\section{Acknowledgements}

The authors would like to thank each woman who took part in this study; who contributed to uncovering the silence on this topic and who were able to shed light on the atrocities that took place in Bosnia \& Herzegovina during the war from 1992-1995. We are indebted to your participation.

\section{References}

Allden, K., Ceriæ, I., Kapetanoviæ, A., Lavelle, J., Loga, S., Mathias, M., ... Sarajliæ, N. (1998). Harvard Trauma Manual: Bosnia-Herzegovina Version. Cambridge (MA): Harvard Program in Refugee Trauma.

Anderson, K., Delić, A., Komproe, I., Avdibegović, E., van Ee, E., \& Glaesmer, H. (2019). Predictors of posttraumatic growth among conflict-related sexual violence survivors from Bosnia and Herzegovina. Conflict and Health, 13(1), 23.

Antičević, V., Kardum, G., \& Britvić, D. (2011). War Veterans' Quality of Life: the Impact of Lifetime Traumatic Experiences, Psychological and Physical Health-Related Characteristics. Drustvena Istrazivanja, 20(4, 114), 1101-1118.

Benard, C. (1994). Rape as Terror: The Case of Bosnia. Terrorism and Political Violence, 6(1), 29-43.

Bosmans, M. G. W., Komproe, I. H., van Loey, N. E., van der Knaap, L. M., Benight, C. C., \& van der Velden, P. G. (2015). Assessing Perceived Ability to Cope With Trauma: a Multigroup Validity Study of a 7-Item Coping Self-Efficacy Scale. European Journal of Psychological Assessment. DOI 10.1027/1015$5759 / \mathrm{a} 000266$.

Brooks, M., Graham-Kevan, N., Robinson, S. \& Lowe M. (2018). Trauma characteristics and posttraumatic growth: The mediating role of avoidance coping, intrusive thoughts, and social support. Psychological Trauma. DOI: 10.1037/tra0000372.

Carver, C. S., Scheier, M. F., \& Weintraub, J. K. (1989). Assessing coping strategies: A theoretically based approach. Journal of Personality and Social Psychology, 56(2), 267-283.

Chivers-Wilson, K. (2006). Sexual assault and posttraumatic stress disorder: a review of the biological, psychological and sociological factors and treatments. McGill Journal of Medicine, 9(2), 111-8.

Cole, A. S. (2008). Differential adjustment among sexual assault survivors: Predicting positive outcome. Department of Psychology: State University of New York at Binghampton. 
Cole, A. S., \& Lynn, S. J. (2010). Adjustment of Sexual Assault Survivors: Hardiness and Acceptance Coping in Posttraumatic Growth. Imagination, Cognition and Personality, 30(1), 111-127.

Dekel, S., Ein-Dor, T., \& Solomon, Z. (2012). Posttraumatic growth and posttraumatic distress: A longitudinal study. Psychological Trauma: Theory, Research, Practice, and Policy, 4(1), 94-101.

Delić, A. (2015). Kvalitete života i dugoročne psihičke posljedice u žena sa iskustvom ratnog silovanja. Univerzitet u Tuzli, Tuzla.

Elderton, A., Berry, A., \& Chan, C. (2017). A Systematic Review of Posttraumatic Growth in Survivors of Interpersonal Violence in Adulthood. Trauma, Violence, and Abuse, 18(2), 223-236.

Folstein, M. F., Folstein, S. E., \& McHugh, P. R. (1975). “Mini-mental state”. A practical method for grading the cognitive state of patients for the clinician. Journal of Psychiatric Research, 12(3), 189-198.

Garcia, D., \& Rimé, B. (2019). Collective Emotions and Social Resilience in the Digital Traces After a Terrorist Attack. Psychological Science, (1993). DOI: 10.1177/0956797619831964

Hudek-Knežević, J., Kardum, I., \& Vukmirović, Ž. (1999). The structure of coping styles: A comparative study of Croatian sample. European Journal of Personality, 13(2), 149-161.

Jennings, K., \& Nikolić-Ristanović, V. (2009). UN Peacekeeping Economies and Local Sex Industries: Connections and Implications. MICROCON Research Working Paper 17. Brighton. DOI:

$10.2139 /$ ssrn. 1488842.

Jöreskog, K. G., \& Sörbom, D. (2006). LISREL 8.80 for Windows (Computer Software). Lincolnwood, IL: Scientific Software International, Inc.

Jordans, M. J. D., Komproe, I. H., Tol, W. A., \& De Jong, J. T. V. M. (2009). Screening for psychosocial distress amongst war-affected children: Cross-cultural construct validity of the CPDS. Journal of Child Psychology and Psychiatry and Allied Disciplines, 50(4), 514-523.

Kamperman, A.M., Komproe, I. H., \& de Jong, J. T. V. M. (2007). Migrant mental health: A model for indicators of mental health and health care consumption. Health Psychology, 26(1), 96-104.

Kılıç, C., Magruder, K. M., \& Koryürek, M. M. (2016). Does trauma type relate to posttraumatic growth after war? A pilot study of young Iraqi war survivors living in Turkey. Transcultural Psychiatry, 53(1), 110-123.

Klaric, M., Franciskovic, T., Klaric, B., Kresic, M., Grkovic, J., Lisica, I., \& Stevanovic, A. (2008). Social support and PTSD symptoms in war-traumatized women in Bosnia and Herzegovina. Psychiatria Danubina, 20(4), 466-473.

Kleim, B., \& Ehlers, A. (2009). Evidence for a Curvilinear Relationship Between Posttraumatic Growth and Posttrauma Depression and PTSD in Assault Survivors. Journal of Traumatic Stress, 22(1), 45-52. 
Kuwert, P., Glaesmer, H., Eichhorn, S., Grundke, E., Pietrzak, R. H., Freyberger, H. J., \& Klauer, T. (2014). Long-term effects of conflict-related sexual violence compared with non-sexual war trauma in female World War II survivors: a matched pairs study. Archives of Sexual Behavior, 43(6), 1059-1064.

Kuwert, P., Klauer, T., Eichhorn, S., Grundke, E., Dudeck, M., Schomerus, G., \& Freyberger, H. J. (2010). Trauma and current posttraumatic stress symptoms in elderly German women who experienced wartime rapes in 1945. Journal of Nervous and Mental Disease, 198(6), 450-451.

Lawrence, J. W., \& Fauerbach, J. A. (2003). Personality, coping, chronic stress, social support and PTSD symptoms among adult burn survivors: A path analysis. The Journal of Burn Care \& Rehabilitation, 24(1), 63-72.

Littleton, H. (2003). The coping process of the unacknowledged rape victim. Department of Psychology: Virginia Polytechnic Institute.

London, M. J., Mercer, M. C., \& Lilly, M. M. (2017). Considering the Impact of Early Trauma on Coping and Pathology to Predict Posttraumatic Growth Among 9-1-1 Telecommunicators. Journal of Interpersonal Violence, 1-13

Maercker, A., \& Zoellner, T. (2004). The Janus Face of Self-Perceived Growth: Toward a Two-Component Model of Posttraumatic Growth. Psychological Inquiry, 15(1), 41-48.

Medica Zenica, \& medica mondiale. (2014). "We are still alive. We have been harmed but we are brave and strong." A research on the long-term consequences of war rape and coping strategies of survivors in Bosnia and Herzegovina. https://doi.org/http://dx.doi.org/10.15498/89451.1

Mittelmark, M. B., \& Bauer, G. F. (2017). The Meanings of Salutogenesis. In The Handbook of Salutogenesis (pp. 7-13). Springer: US.

Mollica, R. F., Caspi-Yavin, Y., Bollini, P., \& Truong, T. (1992). The Harvard trauma questionnaire: Validating a cross-cultural instrument for measuring torture, trauma, and posttraumatic stress disorder in Indochinese refugees. Journal of Nervous and Mental Disease, 180, 111-116.

Mukwege, D. M., \& Nangini, C. (2009). Rape with extreme violence: The new pathology in South Kivu, Democratic Republic of Congo. PLoS Medicine, 6(12), 1-5. http://doi.org/10.1371/journal.pmed.1000204

NICE. (2018). Posttraumatic Stress Disorder: Management. Clinical Guideline. Available at: https://www.nice.org.uk/guidance/cg26/resources/posttraumatic-stress-disorder-management-pdf975329451205. [Date accessed: 11-09-2018].

Salzman, T. (1998). Rape Camps as a Means of Ethnic Cleansing: Religious, Cultural, and Ethical Responses to Rape Victims in the Former Yugoslavia. Human Rights Quarterly, 20(2), 348-378. 
Shakespeare-Finch, J., \& Lurie-Beck, J. (2014). A meta-analytic clarification of the relationship between posttraumatic growth and symptoms of posttraumatic distress disorder. Journal of Anxiety Disorders, 28(2), 223-229.

Skjelsbæk, I. (2006). Victim and survivor: Narrated social identities of women who experienced rape during the war in Bosnia-Herzegovina. Feminism and Psychology, 16(4), 373-403.

Solomon, Z., \& Dekel, R. (2007). Posttraumatic Stress Disorder and Posttraumatic Growth Among Israeli Ex-POWs. Journal of Traumatic Stress, 20(3), 303-312.

Tedeschi, R. G., \& Calhoun, L. G. (1996). The post-traumatic growth inventory: Measuring the positive legacy of trauma. Journal of Traumatic Stress, 9, 455-471.

Tedeschi, R. G., \& Calhoun, L. G. (2004). Posttraumatic Growth: Conceptual Foundations and Empirical Evidence. Psychological Inquiry, 15(1), 1-18.

Tedeschi, R. G., Park, C. \& Calhoun, L. G. (1998). Posttraumatic Growth: Future Directions. In Posttraumatic Growth: Positive Changes in the Aftermath of Crisis (pp. 215-238). Mahwah, NJ: Erlbaum.

Ullman, S. (2014). Correlates of posttraumatic growth in adult sexual assault victims. Trauma, Violence, and Abuse, 20(3), 219-224.

Ulloa, E., Guzman, M. L., Salazar, M., \& Cala, C. (2016). Posttraumatic Growth and Sexual Violence: A Literature Review. Journal of Aggression, Maltreatment \& Trauma, 25(3), 286-304.

United Nations. (2017). Report of the Secretary-General on conflict-related sexual violence. United Nations: Geneva (Vol. 1373).

van Elderen, T., Maes, S., Madalinska, J., \& Komproe, I. H. (1996). Coping, angst en vitale uitputting na een coronair incident. Een longitundinal onderzoek. In Gedrag \& Gezondheid (pp. 207-214).

van Son, M. J. M., Verkerk, G., van der Hart, O., Komproe, I., \& Pop, V. (2005). Prenatal depression, mode of delivery and perinatal dissociation as predictors of postpartum posttraumatic stress: An empirical study. Clinical Psychology and Psychotherapy, 12(4), 297-312.

Verelst, A., De Schryver, M., Broekaert, E., \& Derluyn, I. (2014). Mental health of victims of sexual violence in eastern Congo: associations with daily stressors, stigma, and labeling. BMC Women's Health, 14(1), 106.

Verelst, A., De Schryver, M., De Haene, L., Broekaert, E., \& Derluyn, I. (2014). The mediating role of stigmatization in the mental health of adolescent victims of sexual violence in Eastern Congo. Child Abuse and Neglect, 38(7), 1139-1146. 
Wind, T. R., \& Komproe, I. H. (2012). The mechanisms that associate community social capital with postdisaster mental health: A multilevel model. Social Science and Medicine, 75(9), 1715-1720.

Zoellner, T., \& Maercker, A. (2006). Posttraumatic growth in clinical psychology - A critical review and introduction of a two component model. Clinical Psychology Review, 26(5), 626-653.

Figure Legend

Figure 1

Hypothesised model of relationships between the experience of sexual violence and outcomes PTSD severity and PTG

Figure 2

Tested structural model of relationships between the experience of sexual violence and outcomes PTSD severity and PTG

Figure $2 b$

Optimised structural model of relationships between the experience of sexual violence and outcomes PTSD severity and PTG

Figure 3

Tested structural model of relationships between PTSD severity and PTG-SSVs $(n=104)$

Figure 4

Tested structural model of relationships between PTSD severity and PTG-non-SSVs $(n=81)$

\section{Tables}

\section{Table 1. Demographic characteristics of the study samples}




\begin{tabular}{|c|c|c|c|c|c|}
\hline & \multicolumn{2}{|c|}{$\begin{array}{c}\text { SSVs } \\
(n=104)\end{array}$} & \multicolumn{2}{|c|}{$\begin{array}{c}\text { Non-SSVs } \\
(n=88)\end{array}$} & \multirow[b]{2}{*}{ Statistical test } \\
\hline & Mean & $\mathrm{SD}$ & Mean & $\mathrm{SD}$ & \\
\hline Age & 48.85 & 8.72 & 44.78 & 7.39 & $t=3.44^{*}$ \\
\hline & $n$ & $(\%)$ & $n$ & $(\%)$ & \\
\hline $\begin{array}{l}\text { Ethnicity } \\
\text { Bosnian } \\
\text { Croatian } \\
\text { Serbian } \\
\end{array}$ & $\begin{array}{c}94 \\
5 \\
5 \\
\end{array}$ & $\begin{array}{l}90.4 \\
4.8 \\
4.8 \\
\end{array}$ & $\begin{array}{c}80 \\
6 \\
2 \\
\end{array}$ & $\begin{array}{l}90.9 \\
6.8 \\
2.3\end{array}$ & $\chi \square(2)=1.178$ \\
\hline $\begin{array}{l}\text { Marital status } \\
\text { Married } \\
\text { Single } \\
\text { Widow } \\
\text { Divorced }\end{array}$ & $\begin{array}{l}59 \\
12 \\
22 \\
11\end{array}$ & $\begin{array}{l}56.7 \\
11.5 \\
21.1 \\
10.6\end{array}$ & $\begin{array}{l}71 \\
2 \\
8 \\
7\end{array}$ & $\begin{array}{l}80.7 \\
2.3 \\
9.1 \\
7.9\end{array}$ & $\chi^{\square(3)}=11.440^{*}$ \\
\hline $\begin{array}{l}\text { Education } \\
\text { No schooling } \\
\text { Primary education } \\
\text { Secondary education } \\
\text { Higher education }\end{array}$ & $\begin{array}{c}14 \\
32 \\
52 \\
6\end{array}$ & $\begin{array}{l}13.5 \\
30.8 \\
50.0 \\
5.8\end{array}$ & $\begin{array}{c}1 \\
10 \\
62 \\
15\end{array}$ & $\begin{array}{l}1.1 \\
11.4 \\
70.5 \\
17.0\end{array}$ & $\chi \square(3)=26.375^{*}$ \\
\hline $\begin{array}{l}\text { Work } \\
\text { Employed } \\
\text { Unemployed } \\
\text { Retired } \\
\end{array}$ & $\begin{array}{l}16 \\
71 \\
17 \\
\end{array}$ & $\begin{array}{l}15.4 \\
68.3 \\
16.3 \\
\end{array}$ & $\begin{array}{c}57 \\
28 \\
3 \\
\end{array}$ & $\begin{array}{l}64.8 \\
31.8 \\
3.4\end{array}$ & $\chi^{\square(2)}=50.522^{*}$ \\
\hline & Mean & $\mathrm{SD}$ & Mean & SD & \\
\hline $\begin{array}{l}\text { HTQ (No. events) } \\
\text { HTQ (PTSD severity) }\end{array}$ & $\begin{array}{l}25.52 \\
3.19\end{array}$ & $\begin{array}{l}5.78 \\
.45\end{array}$ & $\begin{array}{l}6.01 \\
1.92\end{array}$ & $\begin{array}{l}5.40 \\
.70\end{array}$ & $\begin{array}{l}t(190)=24.03^{*} \\
t(190)=14.59^{*}\end{array}$ \\
\hline PTGI (total score) & 58.94 & 23.01 & 68.79 & 24.19 & $t(190)=-2.85^{*}$ \\
\hline $\begin{array}{l}\text { COPE Positive reinterpretation } \\
\text { COPE Behavioural disengagement }\end{array}$ & $\begin{array}{l}9.09 \\
8.65\end{array}$ & 3.74 & $\begin{array}{l}10.25 \\
4.81\end{array}$ & $\begin{array}{l}2.96 \\
3.51\end{array}$ & $\begin{array}{l}t(190)=-2.76^{*} \\
t(190)=7.30^{*}\end{array}$ \\
\hline
\end{tabular}

$* p=<.01$

HTQ: No. events, PTSD severity (mean score items 1-16)

PTGI: Posttraumatic growth inventory total score

COPE: Coping Orientations to Problems Experienced Scale (Bosnian)

Table 2. Correlations between the variables specified in the hypothesised model 


\begin{tabular}{|c|c|c|c|c|c|}
\hline & $\begin{array}{l}\text { PTGI } \\
\text { Total } \\
\end{array}$ & $\begin{array}{l}\text { COPE Positive } \\
\text { Reinterpretation }\end{array}$ & $\begin{array}{l}\text { COPE Behavioural } \\
\text { Disengagement }\end{array}$ & $\begin{array}{l}\text { PTSD } \\
\text { Total }\end{array}$ & $\begin{array}{c}\text { SSV vs } \\
\text { non-SSV }\end{array}$ \\
\hline & 1.00 & & & & \\
\hline \multicolumn{6}{|l|}{ PTGI Total } \\
\hline $\begin{array}{l}\text { COPE Positive } \\
\text { Reinterpretation }\end{array}$ & 0.41 & 1.00 & & & \\
\hline $\begin{array}{l}\text { COPE Behavioural } \\
\text { Disengagement }\end{array}$ & -0.25 & -0.26 & 1.00 & & \\
\hline PTSD Total & -0.06 & -0.19 & 0.46 & 1.00 & \\
\hline SSV vs non-SSV* & 0.10 & 0.22 & -0.46 & -0.74 & 1.00 \\
\hline
\end{tabular}

$n=185$

PTGI: Posttraumatic growth inventory total score

PTSD: HTQ (Bosnian) Mean score items 1-16

COPE: Coping Orientations to Problems Experienced Scale (Bosnian)

* point-biserial correlation

\section{Figures}

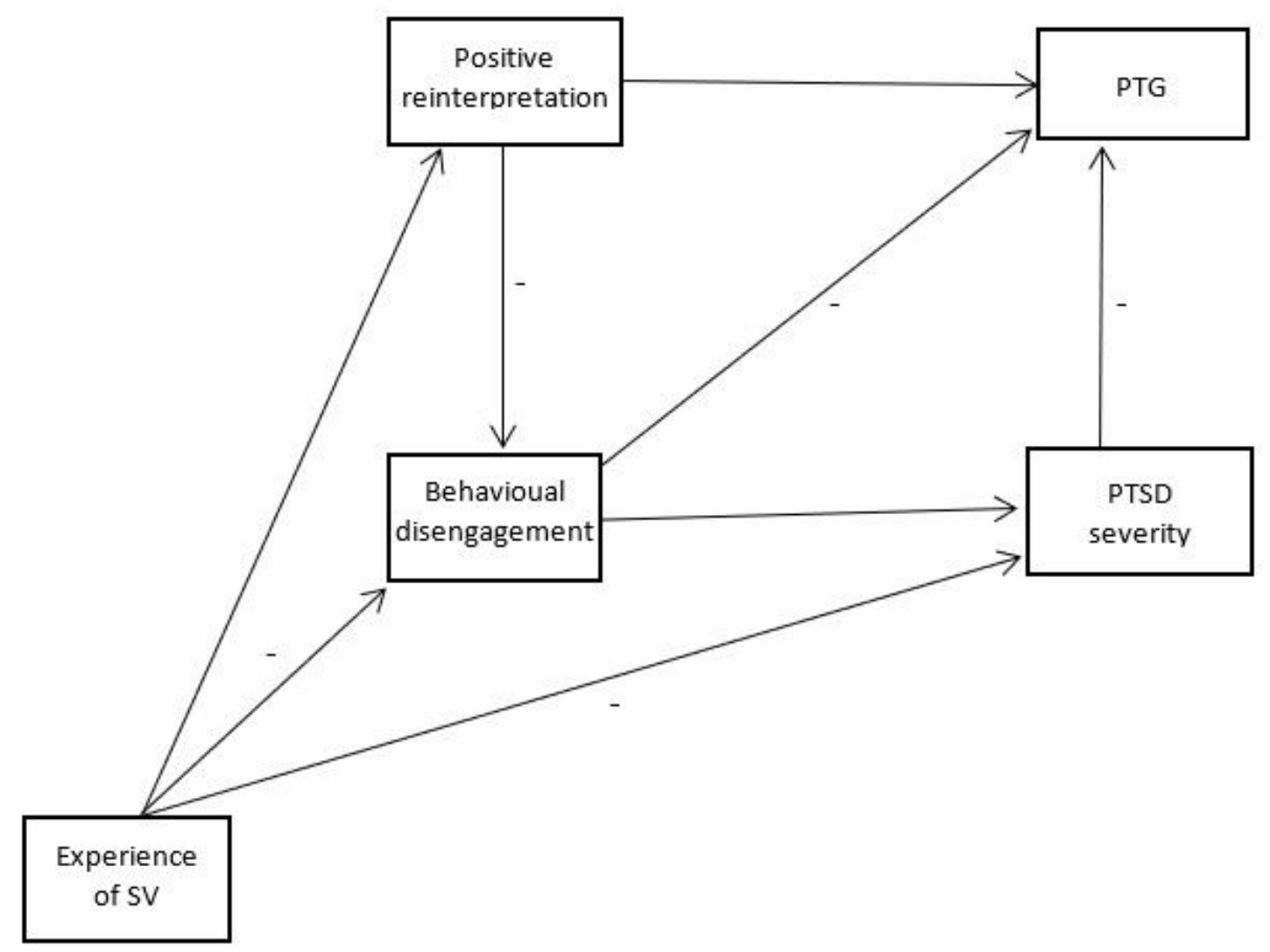

Figure 1 
Hypothesised model of relationships between the experience of sexual violence and outcomes PTSD severity and PTG

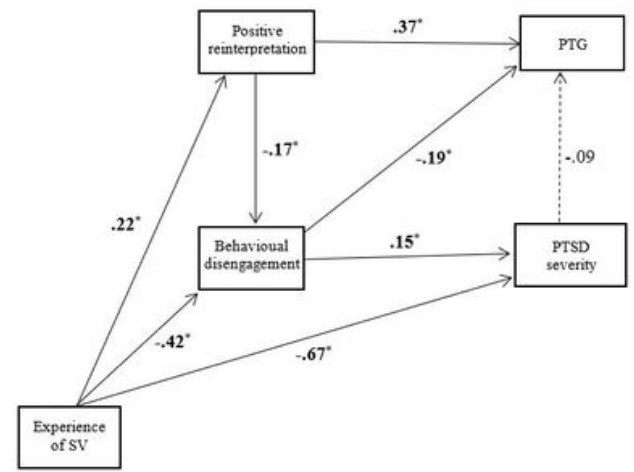

Model fit indices: $x^{2}(3)=10.09, p=<.05 ; 90 \%$ RMSEA $=0.11, \mathrm{CI}=0.038-0.19$

-Standardized estimated paths with a significance of $p<.05$

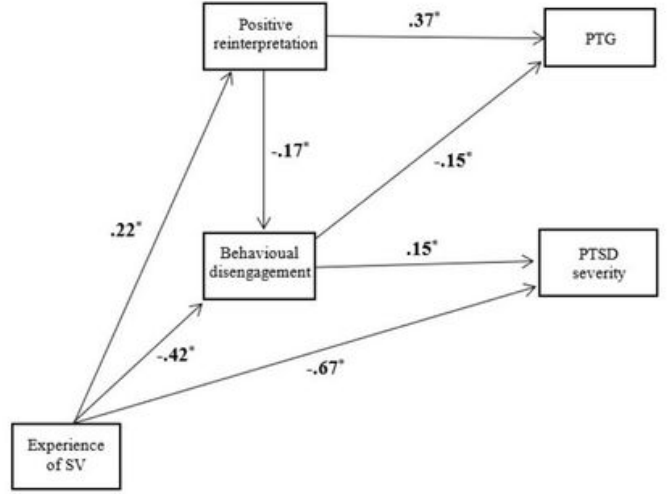

Model fit indices: $\chi 2(3)=10.09, \mathrm{CFI}=.97, \mathrm{RMSEA}=.052$, $\mathrm{SRMR}=.035, \mathrm{NNFI}=90 \mathrm{p}=<.05$ "Standardized estimated paths with a significance of $p<.05$

\section{Figure 2}

Tested structural model of relationships between the experience of sexual violence and outcomes PTSD severity and PTG Optimised structural model of relationships between the experience of sexual violence and outcomes PTSD severity and PTG

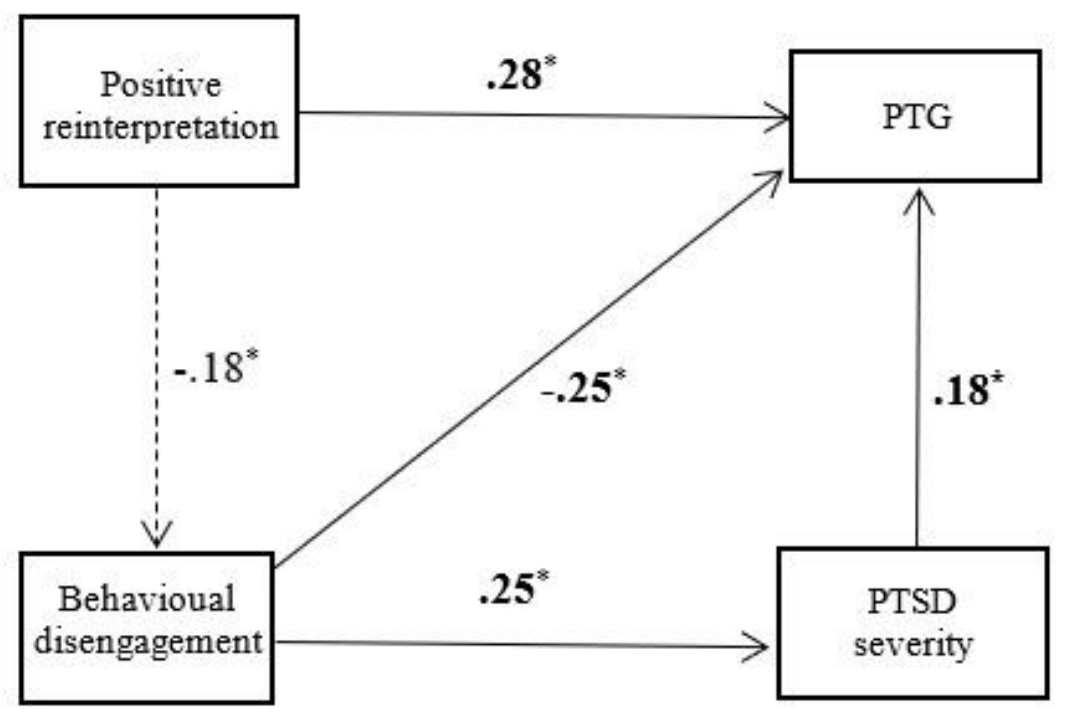

Model fit indices: $\chi 2(1)=1.29, \mathrm{CFI}=.99, \mathrm{RMSEA}=0.11, \mathrm{SRMR}=.036, \mathrm{NNFI}=.93 \mathrm{p}=>.05$

${ }^{*}$ Standardized estimated paths with a significance of $\mathrm{p}<.05$

Figure 3 
Tested structural model of relationships between PTSD severity and PTG - SSVs $(n=104)$

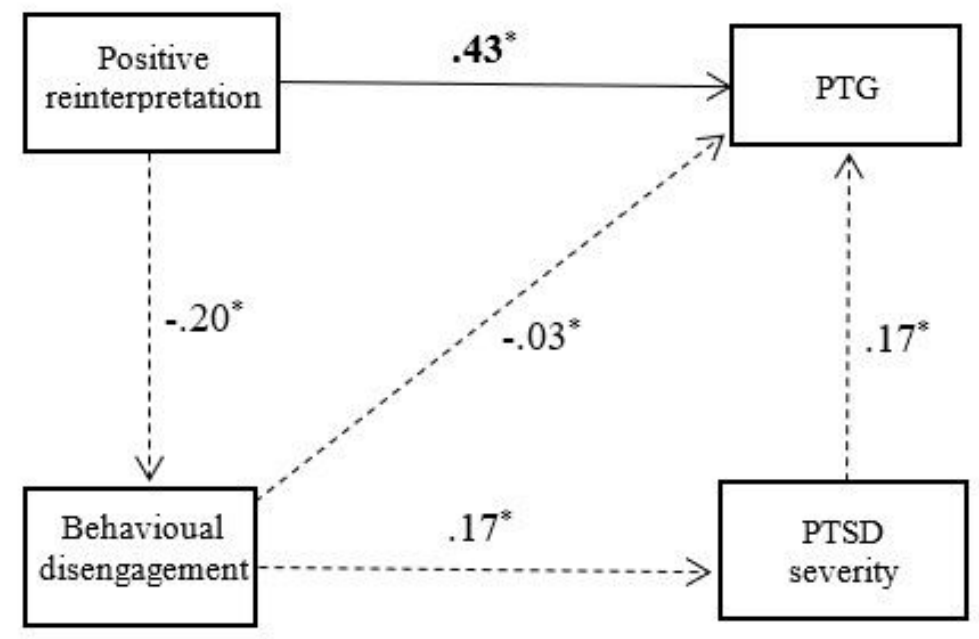

Model fit indices: $\chi^{2}(1)=1.30, \mathrm{CFI}=.98, \mathrm{RMSEA}=0.061, \mathrm{SRMR}=.043, \mathrm{NNFI}=.91, \mathrm{p}=>0.05$

${ }^{*}$ Standardized estimated paths with a significance of $\mathrm{p}<.05$

\section{Figure 4}

Tested structural model of relationships between PTSD severity and PTG - non-SSVs $(n=81)$ 